\title{
A Systematic Review of Digital Versus Analog Drainage for Air Leak Following Surgical Resection or Spontaneous Pneumothorax
}

Fadi Aldaghlawi ${ }^{1}$, Jonathan S. Kurman ${ }^{2}$, Jason A. Lilly ${ }^{3}$, D. Kyle Hogarth ${ }^{4}$, Jessica Donington ${ }^{5}$, Mark K. Ferguson $^{6}$, Septimiu D. Murgu ${ }^{7}$

${ }^{1}$ Assistant Professor of Medicine, Department of Medicine, Indiana University Goshen Health, Goshen, IN: USA

${ }^{2}$ Assistant Professor of Medicine, Department of Medicine, Division of Pulmonary \& Critical Care, Medical College of Wisconsin, Milwaukee, WI: USA

${ }^{3}$ Academic Specialist and Library Systems Manager, Ruth Lilly Medical Library, Indiana University School of Medicine, Indianapolis, IN: USA

${ }^{4}$ Associate Professor of Medicine, Department of Medicine, Section of Pulmonary \& Critical Care, University of Chicago, Chicago, IL: USA

${ }^{5}$ Professor of Surgery, Department of Surgery, Section of Thoracic Surgery, University of Chicago, Chicago, IL: USA

${ }^{6}$ Professor of Surgery, Department of Surgery, Section of Thoracic Surgery, University of Chicago, Chicago, IL: USA

${ }^{7}$ Associate Professor of Medicine, Department of Medicine, Section of Pulmonary \& Critical Care, University of Chicago, Chicago, IL: USA

\section{Corresponding Author}

Septimiu D. Murgu, MD

Associate Professor of Medicine

Co-Director of Bronchoscopy

Director, Interventional Pulmonology Fellowship

Division of Pulmonary \& Critical Care Medicine

University of Chicago Medicine

5841 South Maryland Avenue, M/C 6076

Chicago, Illinois 60637

Email: smurgu@medicine.bsd.uchicago.edu

Telephone: 773-702-0737

\section{Abstract Word Count: 252}

Manuscript Word Count (excluding references): 2376

Conflict of Interest: All authors have no conflicts of interest.

This is the author's manuscript of the article published in final edited form as:

Aldaghlawi, F., Kurman, J. S., Lilly, J. A., Hogarth, D. K., Donington, J., Ferguson, M. K., \& Murgu, S. D. (2020). A Systematic Review of Digital vs Analog Drainage for Air Leak After Surgical Resection or Spontaneous Pneumothorax. Chest. https://doi.org/10.1016/j.chest.2019.11.046 


\title{
Abstract
}

\section{Background:}

The concerns regarding air leak following lung surgery or spontaneous pneumothorax include detection and duration. Prior studies have suggested that digital drainage systems permit a shorter chest tube duration and hospital length of stay (LOS) by earlier detection of air leak cessation. We conducted a systematic review to assess the impact of digital drainage on chest tube duration and hospital LOS following pulmonary surgery and spontaneous pneumothorax.

\section{Methods:}

Ovid MEDLINE, PubMed, Embase, the Cochrane Library, Scopus, and Google Scholar were searched from inception through January 2019. We included randomized controlled trials, cohort studies, and case series of adult patients using digital or traditional drainage devices for air leaks of either postsurgical or spontaneous pneumothorax origin.

\section{Results:}

Of 1,272 references reviewed, 23 articles were included. Nineteen articles addressed post-operative air leak, while 4 articles pertained to air leak after spontaneous pneumothorax. Thirteen studies were randomized controlled trials. Digital drainage resulted in significantly shorter chest tube duration in 8 of 18 studies and shorter hospital LOS in 6 of 14 studies for post-operative air leak. For postpneumothorax air leak, digital drainage resulted in a significantly shorter chest tube duration in 2 of 3 studies and hospital LOS in 1 of 2 studies with an analog control group.

\section{Conclusions:}

Most studies show no significant differences in chest tube duration and hospital LOS with digital versus analog drainage systems for patients with air leak after pulmonary resection. For post spontaneous pneumothorax air leak, the limited published evidence suggests a shorter chest tube duration and hospital LOS with analog drainage systems.

\section{Keywords}

(1) air leak

(2) digital drainage

(3) analog drainage

(4) surgical lung resection

(5) spontaneous pneumothorax

\author{
Abbreviations \\ LOS: length of stay \\ N/A: not applicable \\ RCTs: randomized controlled trials
}




\section{Acknowledgements}

None

\section{Funding}

None

\section{Author Contributions}

I. Conception \& design: FA, SDM

II. Administrative support: none

III. Provision of study materials or patients: none

IV. Collection \& assembly of data: FA, JK, JL, SDM

V. Data analysis \& interpretation: FA, JK, SDM

VI. Manuscript writing: All authors

VII. Final approval of manuscript: All authors 


\section{INTRODUCTION}

Air leak is one of the most common complications following lung surgery, occurring in up to $20 \%$ of cases. ${ }^{1,2}$ A multitude of preventive measures are employed intraoperatively including staples, glues, and fissure last surgery. ${ }^{3-6}$ Approximately $5-10 \%$ of patients continue to have an air leak after 5 days, at which point it is classified as being persistent or prolonged. ${ }^{7}$ Prolonged air leaks are the most common cause of extended hospitalizations and can contribute significantly to cost. ${ }^{8}$ A prolonged air leak may also develop following spontaneous pneumothorax. Surgery is recommended in the vast majority of patients with spontaneous pneumothorax if an air leak persists for more than a few days following chest tube insertion. Patients with unfavorable anatomy or medical comorbidities that make them high risk for surgery, however, may develop prolonged air leak.

An ongoing air leak of any origin typically necessitates continued chest drainage, which may be accomplished using either analog or digital drainage systems. ${ }^{9,10}$ A novel digital drainage system was first introduced in 2007. ${ }^{11}$ Since then, other models have been developed. ${ }^{12}$ These new digital systems have been used to develop standardized algorithms for chest tube management based on objective data. $^{13}$

Analog drainage systems contain a sequentially numbered series of columns in the water seal chamber. The degree of air leak is assessed by observing the highest numbered column in which bubbling occurs. This provides a qualitative assessment at a specific point in time. The standardized assessment developed by Cerfolio can be used to document air leak severity. ${ }^{14}$ This assessment, however, is subject to interobserver variability and does not account for variation over time. Digital drainage systems use electronic sensors to measure changes in pressure and thus may allow for quantification of the degree of air leak continuously and provide a graphical representation of the trend over time. ${ }^{11}$ Data on intrapleural pressure are also provided by some units. Together, these data may lead to expedited chest tube removal and hospital discharge with obvious financial implications.

It is unclear if digital drainage systems are superior to their analog counterparts in terms of managing post-operative and spontaneous air leaks. Individual studies have been limited by small sample size. Trials have demonstrated decreased chest tube duration and hospital length of stay (LOS) with the digital systems. ${ }^{8,13,15,16}$ Two systematic reviews with meta-analysis on the subject have been performed. ${ }^{17,18}$ One review only included randomized controlled trials (RCTs), while the other also included observational studies. Both only included postoperative air leaks. To improve generalizability, we included RCTs, cohort studies, and case series of patients with air leaks of either post-surgical or spontaneous pneumothorax origin. In each patient population, we focused on whether use of a digital versus an analog drainage system reduced chest tube duration and hospital LOS.

\section{METHODS}

\section{Study Identification and Data Sources:}

The following population, intervention, comparison, and outcome (PICO) questions were developed to guide this systematic review:

1. Among patients with an air leak after thoracic surgery, do digital drainage devices compared with conventional drainage devices reduce chest tube duration and/or hospital LOS? 
2. Among patients with an air leak after spontaneous pneumothorax, do digital drainage devices compared with conventional drainage devices reduce chest tube duration and/or hospital LOS?

A comprehensive search of the literature was performed in January 2019 by a medical librarian (JAL) in Ovid MEDLINE, PubMed, Embase, the Cochrane Library, Scopus, and Google Scholar. All databases were searched from inception. Bibliographies of relevant primary studies and systematic reviews were also checked for additional references. Meeting abstracts were reviewed for subsequently published research.

The complete search strategy for each database is reported in Supplement 1. Database-specific subject headings and keyword variants for each of the two major concepts - chest tubes (or their indications) and digital devices - were identified and combined. Results were limited to the English language.

\section{Study Eligibility:}

The following inclusion criteria were used: articles that evaluated the use of the digital drainage devices in adult patients ( $>18$ years of age) with ongoing air leak either after pulmonary surgery or after suffering a spontaneous pneumothorax. The evaluated outcomes included chest tube duration and hospital LOS.

Articles deemed potentially eligible were divided and reviewed by two investigators (FA \& JSK) who independently assessed original research studies for eligibility according to predefined criteria.

Disagreements were resolved after discussion between reviewers.

\section{Exclusion Criteria:}

Systematic reviews, narrative reviews, meta-analyses, comments, case reports, crossover studies, letters, and editorials were excluded. Meeting abstracts were reviewed, and a search was performed for subsequently published research.

\section{Data Abstraction:}

Data were abstracted into an evidence table (Supplement 2), which recorded the following data: study design, patients/follow-up time, type of intervention/comparison, outcomes and adverse events.

\section{Study Quality:}

The quality of each included study was independently evaluated (Supplement 3 ) by two authors (JSK \& SDM) using a modified version of the Downs and Black checklist that was designed for both randomized and nonrandomized studies and has demonstrated good reliability. ${ }^{19,20}$ Discrepancies were resolved by consensus. This validated tool provides an overall score of study quality based on quality of reporting, external validity, internal validity (based on bias and confounding), and power. The checklist consists of 27 items distributed between five sub-scales: (1) Reporting (10 items, 0-11 points), (2) External validity ( 3 items, 0-3 points), (3) Bias (7 items, 0-7 points), (4) Confounding (6 items, 0-6 points), and (5) Power (1 item, 0-1 points). Answers were scored 0 or 1 , except for one item in the reporting subscale, which scored 0 to 2 . The total maximum score is therefore 28 . Score ranges were 
assigned corresponding quality levels as previously reported: excellent (26-28), good (20-25), fair (15$19)$, and poor $(\leq 14) .^{21}$

Odds ratios (OR), median values, and ranges for summary statistics are reported, when available, based on information provided in each of the original studies. Because of the heterogeneity in study type (randomized and nonrandomized), outcome measures, and populations studied, and because few studies provided individual data necessary for quantitative synthesis, no attempt was made to pool data across studies. Therefore, risk of bias across studies was not assessed.

\section{RESULTS}

\section{Study Selection:}

A total of 1,272 references were identified through database queries (Figure 1). After removing 544 duplicates, 728 unique titles and abstracts were screened. Full text review was performed for 49 papers, and of those, 23 were selected for inclusion.

\section{Study Characteristics:}

Patient age, forced expiratory volume (FEV1), smoking history, chest tube reinsertion rate, and the type of procedure(s) performed was collated (Supplements $4 \& 5$ ).

The mean quality index was 21.13 , with a range of $15-25$. Based on the score ranges discussed above, 16 and 7 articles were classified as good and fair, respectively. No articles were deemed to be excellent or poor. Nineteen articles addressed PICO question \#1, while four articles pertained to PICO question \#2. Thirteen studies were RCTs.

\section{Post-Operative Air Leak: \\ Chest Tube Duration:}

Data for chest tube duration for post-operative air leak were provided in 19 studies and are presented in Table 1. An analog control group was not included in one study. ${ }^{30}$ Digital systems resulted in a significantly shorter chest tube duration in 8 of those studies. ${ }^{15,16,23-26,38,40}$ The mean chest tube duration ranged from 1.7 to 5.5 days with the digital system and from 1.9 to 6.1 days with the analog system.

\section{Hospital Length of Stay:}

Data on hospital LOS for post-operative air leak were provided in 15 studies and are presented in Table 2. An analog control group was not included in one study. ${ }^{30}$ Of the 14 studies that include an analog control group, digital systems resulted in a significantly shorter LOS in 6 of them. ${ }^{15,16,23,25,32,38}$ Mean LOS ranged from 3.3 to 6.5 days with the digital system and from 3.9 to 9.0 days with the analog system.

\section{Air Leak After Spontaneous Pneumothorax: Chest Tube Duration:}


Data for chest tube duration for air leak following spontaneous pneumothorax were provided in four studies and are presented in Table $3 .^{33-36}$ In two of the three studies that included an analog control group, the digital systems resulted in a significantly shorter chest tube duration. ${ }^{33,37}$ The mean chest tube duration ranged from 47 to 96 hours with the digital system and from 74 to 94 hours with the analog system.

\section{Hospital Length of Stay:}

Data for hospital LOS for air leak following spontaneous pneumothorax were provided in three studies and are presented in Table 4. ${ }^{33,35,36}$ In the two studies that include an analog control group, only one demonstrated a significantly shorter hospital LOS with the digital system. ${ }^{33}$ Mean LOS ranged from 3.5 to 5.1 days with the digital system and from 4.0 to 7.0 days with the analog system.

\section{DISCUSSION}

Air leak remains one of the most common complications after pulmonary resections. ${ }^{1,2}$ Postoperative air leaks often necessitate extended hospitalization periods and inevitably increase costs. Air leaks may also complicate spontaneous pneumothorax in patients with comorbidities or unfavorable anatomy that precludes surgery. The advent of digital drainage systems over the past decade has the potential to alter the framework of chest tube management. This systematic review demonstrated inconsistent benefits in chest tube duration and hospital LOS with digital drainage systems. In the post-operative setting, $44 \%$ of studies identified a statistically significantly shorter chest tube duration with the digital drainage system. This value increased to $66 \%$ in the post-pneumothorax setting. Hospital LOS was statistically significantly shorter in $42 \%$ of studies in the post-operative setting. This value increased slightly to $50 \%$ in the post-pneumothorax population.

Prior studies have suggested that digital drainage systems permit a shorter chest tube duration and LOS, but definitive conclusions have been limited by small sample size. ${ }^{8,13,15,16}$ Only two systematic reviews with metanalysis has been performed for digital drainage systems, and only RCTs and observational studies involving postoperative air leaks were included. ${ }^{17,18}$

This systematic review of digital drainage systems is the largest to date and is the first to include postpneumothorax air leaks. Our analysis included RCTs, cohort studies, and case series involving both postoperative and post-pneumothorax air leaks in order to improve generalizability and applicability in clinical practice. Prior metanalyses only included RCTs and observation studies. The strength of our conclusions was impacted by the results of our quality index assessment.

Well defined PICO questions were designed to address these two unique clinical problems. A total of 23 articles are included, and the results are stratified by etiology. Most articles focused on postoperative air leaks, where the digital drainage system sometimes resulted in shorter chest tube duration and shorter hospital LOS. With post-pneumothorax air leak, digital drainage systems resulted in a shorter chest tube duration in two of three studies and a shorter hospital LOS in one of two studies. $^{33,34}$

Digital drainage systems may result in a shorter chest tube duration and hospital LOS for several reasons. First, by tracking the intrapleural pressure, digital systems may be able to distinguish a true 
air leak from an obligatory space. Second, by quantifying the degree of air flow over a period of time, providers may feel more comfortable with earlier removal of a chest tube.

Although earlier chest tube removal is an admirable goal, it is only beneficial if re-insertion is not required. Data on chest tube re-insertion rate or pneumothorax recurrence rate were provided in 11 of the 23 studies (Supplement 4). The rate was not statistically significantly different between the digital and analog drainage groups in the post-operative cohort in any study. In the one study that included these data in the post-pneumothorax group, however, there was a statistically significant difference favoring the digital drainage group $(4.4 \%$ vs $14 . \%, p=0.041) .{ }^{35}$

Our study has multiple limitations. First, while its inclusivity improves generalizability, the heterogeneity of the studies precludes metanalysis. Second, numerous factors, such as FEV1, which lobe is resected, and the type of resection (segmentectomy, lobectomy, bi-lobectomy, etc.) impact chest tube duration and hospital LOS. These variables were selected because they are the most commonly studied variables in the literature on this topic. It is possible, however that changes in chest tube duration and hospital LOS may not be solely attributable to a particular drainage system. Early mobilization is safe and may reduce postoperative complications following pulmonary resection. ${ }^{45,46}$ Third, only a limited number of studies include post-pneumothorax patients so the data in this scenario are less robust. Fourth, the LOS metric is potentially problematic because some surgeons will discharge a patient the same day a chest tube is removed, while others will wait until the following day. Some patients may even be discharged with a chest tube in place. Fifth, published data may be skewed by a negative outcomes publication bias. Thus, studies demonstrating equivocal or inferior outcomes with digital drainage systems may be underrepresented.

Cost effectiveness is an essential concern for an ideal chest drainage system. Our analysis did not address cost effectiveness of the two drainage systems. Cost data for post-operative air leak was provided in three studies. ${ }^{25,33,36}$ In two of these studies, there was a statistically significant difference in cost between the digital and analog systems. ${ }^{38}$ The digital system resulted in a significant reduction in hospital costs, with average savings of $€ 476$ to $€ 751$. Data on cost were available in one study involving patients with air leak following spontaneous pneumothorax and also showed significant cost savings. ${ }^{33}$ Mean treatment cost was lower by $22.34 \%$, which saved roughly $€ 430$ per patient. Given the decrease in chest tube duration and hospital LOS, we suspect that the use of digital systems could be costeffective in the long-term, despite the high initial expenditure. However, the vast majority of patients undergoing lung resection do not develop an air leak, so the use of digital systems in those patients adds cost without benefit. If there is a clear advantage of digital systems in selected patients, the next task is to identify those patients before the more expensive system is selected for drainage and routinely implemented in clinical practice.

\section{CONCLUSION}

Digital drainage systems provide clinicians with a more accurate assessment of a patient's air leak. Most studies show no statistically significant differences in chest tube duration and hospital LOS with digital versus analog drainage systems for patients with air leak after pulmonary resection. For post spontaneous pneumothorax air leak, the limited published evidence suggests a shorter chest tube duration and hospital LOS with the analog systems. Additional research is required to evaluate time to chest tube removal, LOS, and costs of using digital drainage systems for patients with air leak. 


\section{REFERENCES}

1. Brunelli A, Monteverde M, Borri A, et al. Predictors of prolonged air leak after pulmonary lobectomy. Ann of Thorac Surg. 2004;77(4):1205-1210.

2. Rice TW, Okereke IC, Blackstone EH. Persistent air-leak following pulmonary resection. Chest Surg Clin N Am. 2002;12(3):529-539.

3. Cardillo G, Carleo F, Carbone L, et al. Adverse effects of fibrin sealants in thoracic surgery: the safety of a new fibrin sealant: multicentre, randomized, controlled, clinical trial. Eur J Cardiothorac Surg. 2012;41(3):657-662.

4. Miller JI Jr, Landreneau RJ, Wright CE, et al. A comparative study of buttressed versus nonbuttressed staple line in pulmonary resections. Ann Thorac Surg. 2001;71(1):319-323.

5. Stamenovic D, Bostanci K, Messerschmidt A, et al. Fissureless fissure-last video-assisted thoracoscopic lobectomy for all lung lobes: a better alternative to decrease the incidence of prolonged air leak? Eur J Cardiothorac Surg. 2016;50(1):118-123.

6. Fabian T, Federico JA, Ponn RB. Fibrin glue in pulmonary resection: a prospective, randomized, blinded study. Ann Thorac Surg. 2003;75(5):1587-1592.

7. Cerfolio RJ, Bass CS, Pask AH, et al. Predictors and treatment of persistent air leaks. Ann Thorac Surg. 2002;73(6):1727-1731.

8. Cerfolio RJ, Bryant AS. The benefits of continuous and digital air leak assessment after elective pulmonary resection: a prospective study. Ann Thorac Surg. 2008;86(2):396-401.

9. Lang $P$, Manickavasagar $M$, Burdett $C$, et al. Suction on chest drains following lung resection: evidence and practice are not aligned. Eur J Cardiothorac Surg. 2016;49(2):611-616.

10. Brunelli A, Sabbatini A, Xiumé F, et al. Alternate suction reduces prolonged air leak after pulmonary lobectomy: a randomized comparison versus water seal. Ann Thorac Surg. 2005;80(3):1052-1055.

11. Dernevik L, Belboul A, Rådberg G. Initial experience with the world's first digital drainage system. The benefits of recording air leaks with graphic representation. Eur J Cardiothorac Surg. 2007;31(2):209-213.

12. Satoh Y. Management of chest drainage tubes after lung surgery. Gen Thorac Cardiovasc Surg. 2016;64(6):305-308.

13. Brunelli A, Salati M, Refai M, et al. Evaluation of a new chest tube removal protocol using digital air leak monitoring after lobectomy: a prospective randomised trial. Eur J Cardiothorac Surg. 2010;37(1):56-60.

14. Cerfolio RJ. Advances in thoracostomy tube management. Surg Clin North Am. 2002;82(4):833848. 
15. Filosso PL, Nigra VA, Lanza G, et al. Digital versus traditional air leak evaluation after elective pulmonary resection: a prospective and comparative mono-institutional study. $J$ Thorac Dis. 2015;7(10):1719-1724.

16. Pompili C, Detterbeck F, Papagiannopoulos K, et al. Multicenter international randomized comparison of objective and subjective outcomes between electronic and traditional chest drainage systems. Ann Thorac Surg. 2014;98(2):490-497.

17. Zhou J, Lyu M, Chen N, et al. Digital chest drainage is better than traditional chest drainage following pulmonary surgery: a meta-analysis. Eur J Cardiothorac Surg. 2018;54(4):635-643.

18. Wang $\mathrm{H}, \mathrm{Hu} \mathrm{W}, \mathrm{Ma} \mathrm{L}, \mathrm{Zhang} \mathrm{Y}$. Digital chest drainage system versus traditional chest drainage system after pulmonary resection: a systematic review and meta-analysis. J Cardiothorac Surg. 2019;14:13.

19. Downs $\mathrm{SH}$, Black N. The feasibility of creating a checklist for the assessment of the methodological quality both of randomised and non-randomised studies of health care interventions. J Epidemiol Community Health. 1998;52(6):377-384.

20. Korakakis V, Whiteley R, Tzavara A, et al. The effectiveness of extracorporeal shockwave therapy in common lower limb conditions: a systematic review including quantification of patient-rated pain reduction. Br J Sports Med. 2018;52(6):387-407.

21. Hooper P, Jutai JW, Strong G, et al. Age-related macular degeneration and low-vision rehabilitation: a systematic review. Can J Ophthalmol. 2008;43(2):180-187.

22. Bertolaccini L, Rizzardi G, Filice MJ, et al. "Six sigma approach" - an objective strategy in digital assessment of postoperative air leaks: a prospective randomised study. Eur J Cardiothorac Surg. 2011;39(5):e128-132.

23. Miller DL, Helms GA, Mayfield WR. Digital drainage system reduces hospitalization after videoassisted thoracoscopic surgery lung resection. Ann Thorac Surg. 2016;102(3):955-961.

24. Shoji F, Takamori S, Akamine T, et al. Clinical evaluation and outcomes of digital chest drainage after lung resection. Ann Thorac Cardiovasc Surg. 2016;22(6):354-358.

25. Pompili C, Brunelli A, Salati M, et al. Impact of the learning curve in the use of a novel electronic chest drainage system after pulmonary lobectomy: a case-matched analysis on the duration of chest tube usage. Interact Cardiovasc Thorac Surg. 2011;13(5):490-493.

26. Mier JM, Molins L, Fibla JJ. The benefits of digital air leak assessment after pulmonary resection: prospective and comparative study. Cir Esp. 2010;87(6):385-389.

27. Plourde $\mathrm{M}$, Jad A, Dorn $\mathrm{P}$, et al. Digital air leak monitoring for lung resection patients: a randomized controlled clinical trial. Ann Thorac Surg. 2018;106(6):1628-1632.

28. Arai H, Tajiri M, Kameda Y, et al. Evaluation of a digital drainage system (Thopaz) in over 250 cases at a single site: A retrospective case-control study. Clin Respir J. 2017;12(4):1454-1459. 
29. Marjański T, Sternau A, Rzyman W. The implementation of a digital chest drainage system significantly reduces complication rates after lobectomy - a randomized clinical trial. KITP. 2013;2:133-138.

30. Marasco RD, Giudice G, Lequaglie $C$. How to distinguish an active air leak from a pleural space effect. Asian Cardiovasc Thorac Ann. 2012;20(6):682-688.

31. Gilbert S, McGuire AL, Maghera S, et al. Randomized trial of digital versus analog pleural drainage in patients with or without a pulmonary air leak after lung resection. $J$ Thorac Cardiovasc Surg. 2015;150(5):1243-1249.

32. Filosso PL, Ruffini E, Solidoro $\mathrm{P}$, et al. Digital air leak monitoring after lobectomy for primary lung cancer in patients with moderate COPD: can a fast-tracking algorithm reduce postoperative costs and complications? J Cardiovasc Surg. 2010;51(3):429-433.

33. Jablonski S, Brocki M, Wawrzycki M, et al. Efficacy assessment of the drainage with permanent airflow measurement in the treatment of pneumothorax with air leak. Thorac and Cardiovasc Surgeon. 2014;62(06):509-515.

34. Cho HM, Hong YJ, Byun CS, et al. The usefulness of Wi-Fi based digital chest drainage system in the post-operative care of pneumothorax. J Thorac Dis. 2016;8(3):396-402.

35. Pompili C, Xiumé $F$, Hristova $R$, et al. Regulated drainage reduces the incidence of recurrence after uniportal video-assisted thoracoscopic bullectomy for primary spontaneous pneumothorax: a propensity case-matched comparison of regulated and unregulated drainage. Eur J Cardiothorac Surg. 2016;49(4):1127-1131.

36. Tunnicliffe G, Draper A. A pilot study of a digital drainage system in pneumothorax. BMJ Open Respir Res 2014;1(1):e000033.

37. Cho MH, Malhotra A, Donahue DM, et al. Mechanical ventilation and air leaks after lung biopsy for acute respiratory distress syndrome. Ann Thorac Surg. 2006;82(1):261-266.

38. Brunelli A, Salati M, Refai M, et al. Evaluation of a new chest tube removal protocol using digital air leak monitoring after lobectomy: a prospective randomised trial. Eur J Cardiothorac Surg. 2010;37(1):56-60.

39. Lijkendijk M, Licht PB, Neckelmann K. Electronic versus traditional chest tube drainage following lobectomy: a randomized trial. Eur J Cardiothorac Surg. 2015;48(6):893-898.

40. Cerfolio RJ, Bryant AS. The benefits of continuous and digital air leak assessment after elective pulmonary resection: a prospective study. Ann Thorac Surg. 2008;86(2):396-401.

41. De Waele M, Agzarian J, Hanna WC, et al. Does the usage of digital chest drainage systems reduce pleural inflammation and volume of pleural effusion following oncologic pulmonary resection? - a prospective randomized trial. J Thorac Dis. 2017;9(6):1598-1606.

42. Arai $\mathrm{H}$, Tajiri $\mathrm{M}$, Kameda $\mathrm{Y}$, et al. Evaluation of a digital drainage system (Thopaz) in over 250 cases at a single site: a retrospective case-control study. Clin Respir J. 2017;12(4):1454-1459. 
43. Takamochi $\mathrm{K}$, Nojiri S, Oh S, et al. Comparison of digital and traditional thoracic drainage systems for postoperative chest tube management after pulmonary resection: a prospective randomized trial. J Thorac Cardiovasc Surg. 2018;155(4):1834-1840.

44. Chiappetta M, Lococo F, Nachira D, et al. Digital devices improve chest tube management: results from a prospective randomized trial. Thorac Cardiovasc Surg. 2018;66(7):595-602.

45. van der Leeden M, Balland C, Geleijn E, et al. In-hospital mobilization, physical fitness, and physical functioning after lung cancer surgery. Ann Thorac Surg. 2019;107(6):1639-1646.

46. Jonsson $M$, Ahlsson A, Hurtig-Wennlöf A, et al. In-hospital physiotherapy and physical recovery 3 Months after lung cancer surgery: a randomized controlled trial. Integr Cancer Ther 2019;18:1-9. 
Table 1. Mean chest tube duration with analog and digital drainage for post-operative air leak. Ranges and standard deviation are provided when available. Data for multiple digital drainage systems are presented when available. The mode is listed when the mean was not provided.

\begin{tabular}{|c|c|c|c|}
\hline \multirow{2}{*}{ Study } & \multicolumn{2}{|c|}{ Chest Tube Duration } & \multirow{2}{*}{$p$-value } \\
\hline & Digital Drainage (days) & Analog Drainage (days) & \\
\hline Gilbert et al. $(2015)^{31}$ & $4.9(3.1-6.4)$ & $5.6(4.0-8.9)$ & 0.11 \\
\hline $\begin{array}{l}\text { Lijkendijk et al. } \\
(2015)^{39}\end{array}$ & $1.7(0.9-2.8)$ & $1.9(1.0-2.9)$ & 0.397 \\
\hline $\begin{array}{l}\text { Bertolaccini et al. } \\
(2011)^{22}\end{array}$ & $5.5 \pm 0.7$ & $6.1 \pm 0.8$ & 0.056 \\
\hline Filosso et al. $(2010)^{32}$ & 4.0 (mode) & 5.0 (mode) & Not provided \\
\hline Brunelli et al. $(2010)^{38}$ & $4.0 \pm 3.6$ & $4.9 \pm 4.0$ & 0.0007 \\
\hline Cerfolio et al. $(2008)^{40}$ & 3.1 & 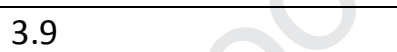 & 0.034 \\
\hline Filosso et al. $(2015)^{15}$ & $3.0 \pm 1.5$ & $4.0 \pm 1.9$ & 0.0009 \\
\hline Miller et al. $(2016)^{23}$ & $3.7(1.9-6.1)$ & $5.3(2.8-8.8)$ & 0.01 \\
\hline $\begin{array}{l}\text { De Waele et al. } \\
(2017)^{41}\end{array}$ & 2.3 & 2.5 & 0.055 \\
\hline Pompili et al. $(2014)^{16}$ & 3.6 & 4.7 & 0.0001 \\
\hline $\begin{array}{l}\text { Marasco et al. } \\
(2012)^{30}\end{array}$ & 4.5 & N/A & $\mathrm{N} / \mathrm{A}$ \\
\hline Shoji et al. $(2016)^{24}$ & $2.7(1-9)$ & $3.7(1-20)$ & 0.031 \\
\hline Arai et al. $(2017)^{42}$ & $2.4 \pm 2.2$ & $2.3 \pm 2.2$ & 0.678 \\
\hline Pompili et al. $(2011)^{25}$ & 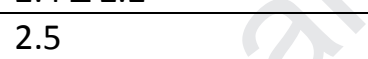 & 4.4 & $<0.0001$ \\
\hline $\begin{array}{l}\text { Marjanski et al. } \\
(2013)^{29}\end{array}$ & 4.0 & 4.0 & 0.919 \\
\hline Mier et al. $(2010)^{26}$ & $2.4 \pm 1.0 \& 3.3 \pm 1.0$ & $4.5 \pm 3.6$ & $0.00 \& 0.47$ \\
\hline $\begin{array}{l}\text { Takamochi et al. } \\
(2018)^{43}\end{array}$ & $2.0(2-3)$ & $3.0(2-4)$ & 0.149 \\
\hline $\begin{array}{l}\text { Chiappetta et al. } \\
(2018)^{44}\end{array}$ & $4.1 \pm 2.0$ & $4.6 \pm 3.5$ & 0.4 \\
\hline Plourde et al. $(2018)^{27}$ & $3.0(2-5)$ & $3.0(3-5)$ & 0.20 \\
\hline
\end{tabular}


Table 2. Mean hospital LOS with analog and digital drainage for post-operative air leak. Ranges and standard deviation are provided when available.

\begin{tabular}{|c|c|c|c|}
\hline \multirow{2}{*}{ Study } & \multicolumn{2}{|c|}{ Hospital LOS } & \multirow{2}{*}{$p$-value } \\
\hline & Digital Drainage (days) & Analog Drainage (days) & \\
\hline Gilbert et al. $(2015)^{31}$ & $6.2(4-8)$ & $6.2(5-9)$ & 0.36 \\
\hline $\begin{array}{l}\text { Lijkendijk et al. } \\
(2015)^{39}\end{array}$ & $4.0(3-5)$ & $5.0(3-6)$ & 0.651 \\
\hline $\begin{array}{l}\text { Bertolaccini et al. } \\
(2011)^{22}\end{array}$ & $6.5 \pm 0.5$ & $7.1 \pm 0.4$ & 0.09 \\
\hline Filosso et al. $(2010)^{32}$ & 6.0 (mode) & 9.0 (mode) & 0.00001 \\
\hline Brunelli et al. $(2010)^{38}$ & $5.4 \pm 2.2$ & $6.3 \pm 2.9$ & 0.007 \\
\hline Cerfolio et al. $(2008)^{40}$ & 3.3 & 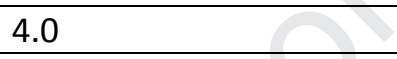 & 0.055 \\
\hline Filosso et al. $(2015)^{15}$ & $7.0 \pm 3.0$ & $8.0 \pm 2.6$ & 0.0385 \\
\hline Miller et al. $(2016)^{23}$ & $4.1(2.1-6.7)$ & $5.6(4.0-10.3)$ & 0.05 \\
\hline $\begin{array}{l}\text { De Waele et al. } \\
(2017)^{41}\end{array}$ & 4.8 & 4.9 & 0.403 \\
\hline Pompili et al. $(2014)^{16}$ & 4.6 & 5.6 & $<0.0001$ \\
\hline $\begin{array}{l}\text { Marasco et al. } \\
(2012)^{30}\end{array}$ & $6.1(2-20)$ & N/A & $\mathrm{N} / \mathrm{A}$ \\
\hline Pompili et al. $(2011)^{25}$ & 4.5 & 6.0 & 0.0003 \\
\hline $\begin{array}{l}\text { Takamochi et al. } \\
(2018)^{43}\end{array}$ & $6.0(6-8)$ & $7.0(6-8)$ & 0.548 \\
\hline $\begin{array}{l}\text { Chiappetta et al. } \\
(2018)^{44}\end{array}$ & $5.8 \pm 2.5$ & $6.2 \pm 4.2$ & 0.5 \\
\hline Plourde et al. $(2018)^{27}$ & $4.0(3-7)$ & $5.0(3-7)$ & 0.47 \\
\hline
\end{tabular}


Table 3. Mean chest tube duration with analog and digital drainage for air leak secondary to spontaneous pneumothorax. Ranges and standard deviation are provided when available.

\begin{tabular}{|l|l|l|l|}
\hline \multirow{2}{*}{ Study } & \multicolumn{2}{|c|}{ Chest Tube Duration } & \multirow{2}{*}{ p-value } \\
\cline { 2 - 4 } & Digital Drainage (hours) & Analog Drainage (hours) & 0.000039 \\
\hline $\begin{array}{l}\text { Jablonski et al. } \\
(2014)^{33}\end{array}$ & $47 \pm 24(16-121)$ & $84 \pm 36(34-169)$ & 0.006 \\
\hline $\begin{array}{l}\text { Cho et al. } \\
(2016)^{34}\end{array}$ & 52 & 74 & 0.55 \\
\hline $\begin{array}{l}\text { Pompili et al. } \\
(2016)^{35}\end{array}$ & $86 \pm 52$ & $93 \pm 74$ & N/A \\
\hline $\begin{array}{l}\text { Tunniclife et al. } \\
(2014)^{36}\end{array}$ & $96(24-696)$ & N/A & \\
\hline
\end{tabular}


Table 4. Mean hospital LOS with analog and digital drainage for air leak secondary to spontaneous pneumothorax. Ranges and standard deviation are provided when available.

\begin{tabular}{|l|l|l|l|}
\hline \multirow{2}{*}{ Study } & \multicolumn{2}{|c|}{ Hospital LOS } & \multirow{2}{*}{ p-value } \\
\cline { 2 - 4 } & Digital Drainage (days) & Analog Drainage (days) & \\
\hline $\begin{array}{l}\text { Jablonski et al. } \\
(2014)^{33}\end{array}$ & $5.1 \pm 1.09(3-8)$ & $7.0 \pm 1.96(4-11)$ & $<0.0005$ \\
\hline $\begin{array}{l}\text { Pompili et al. } \\
(2016)^{35}\end{array}$ & $4.4 \pm 2.0$ & $3.9 \pm 2.2$ & 0.16 \\
\hline $\begin{array}{l}\text { Tunniclife et al. } \\
(2014)^{36}\end{array}$ & $3.5(1-92)$ & N/A & N/A \\
\hline
\end{tabular}


Figure 1. Flow diagram of study selection.

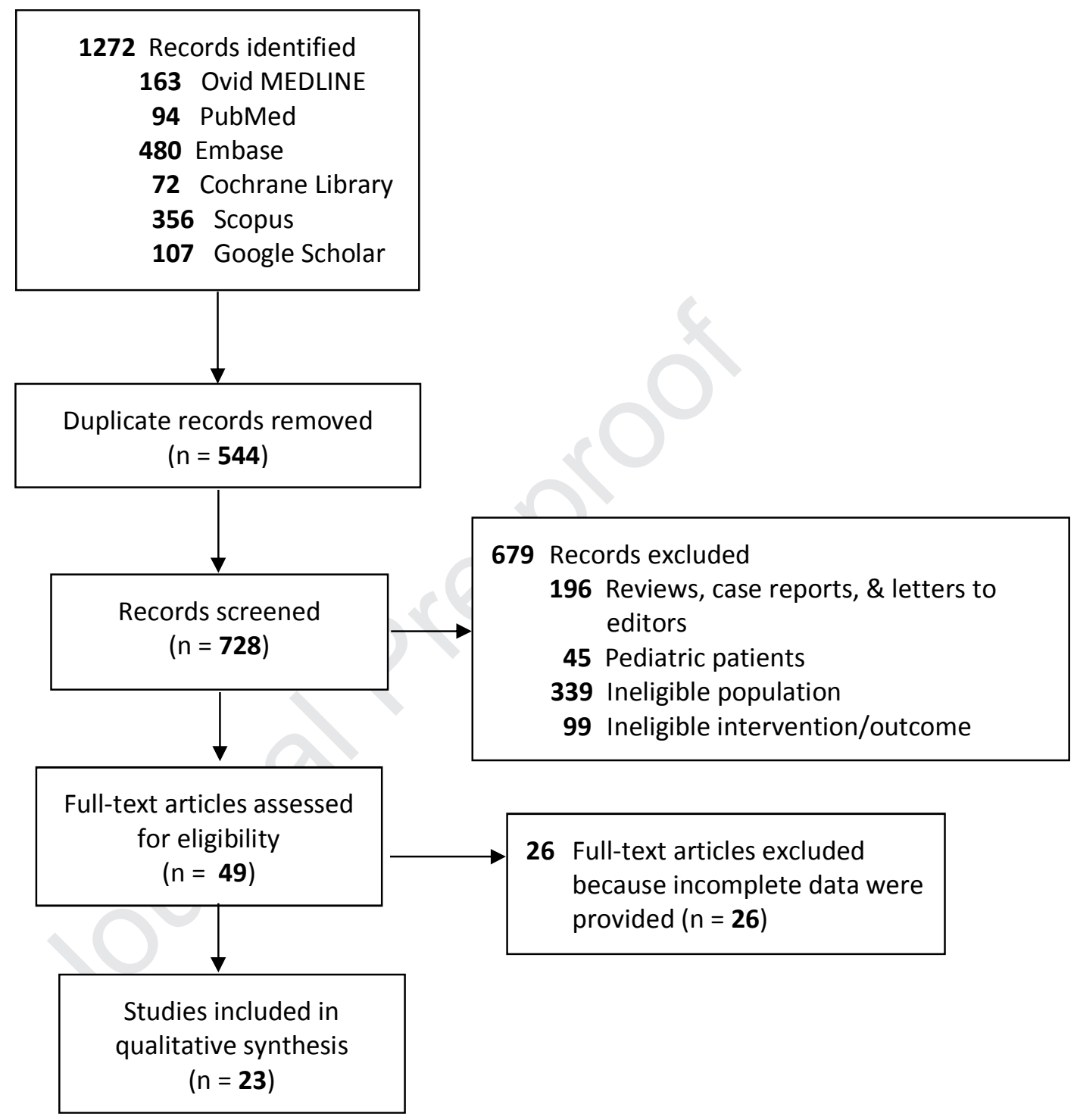

